Check for updates

Cite this: Chem. Sci., 2020, 11, 435

๑ All publication charges for this article have been paid for by the Royal Society of Chemistry

Received 12th September 2019 Accepted 12th November 2019

DOI: $10.1039 / c 9 s c 04589 a$

rsc.li/chemical-science

\title{
Carbene metal amide photoemitters: tailoring conformationally flexible amides for full color range emissions including white-emitting OLED $\uparrow$
}

\author{
Alexander S. Romanov, (D)*a Saul T. E. Jones, (D) ${ }^{\mathrm{b}}$ Qinying Gu, (D) b \\ Patrick J. Conaghan, (iD ${ }^{\mathrm{b}}$ Bluebell H. Drummond, (iD) ${ }^{\mathrm{b}}$ Jiale Feng, (D) $\mathrm{b}$ \\ Florian Chotard, (D) a Leonardo Buizza, (D) ${ }^{\mathrm{b}}$ Morgan Foley, (D) ${ }^{\mathrm{b}}$ Mikko Linnolahti, (D) *c \\ Dan Credgington (iD) ${ }^{* b}$ and Manfred Bochmann (D)*a
}

\begin{abstract}
Conformationally flexible "Carbene-Metal-Amide" (CMA) complexes of copper and gold have been developed based on a combination of sterically hindered cyclic (alkyl)(amino)carbene (CAAC) and 6- and 7 -ring heterocyclic amide ligands. These complexes show photoemissions across the visible spectrum with $\mathrm{PL}$ quantum yields of up to $89 \%$ in solution and $83 \%$ in host-guest films. Single crystal $\mathrm{X}$-ray diffraction and photoluminescence $(\mathrm{PL})$ studies combined with DFT calculations indicate the important role of ring structure and conformational flexibility of the amide ligands. Time-resolved PL shows efficient delayed emission with sub-microsecond to microsecond excited state lifetimes at room temperature, with radiative rates exceeding $10^{6} \mathrm{~s}^{-1}$. Yellow organic light-emitting diodes (OLEDs) based on a 7-ring gold amide were fabricated by thermal vapor deposition, while the sky-blue to warm-white mechanochromic behavior of the gold phenothiazine-5,5-dioxide complex enabled fabrication of the first CMA-based white light-emitting OLED.
\end{abstract}

\section{Introduction}

Two-coordinate coinage metal complexes with linear geometry (L)MX ( $\mathrm{L}=$ carbene; $\mathrm{M}=\mathrm{Cu}, \mathrm{Ag}$ or $\mathrm{Au} ; \mathrm{X}=$ anionic ligand) have recently emerged as a new class of strongly photoemissive materials. ${ }^{\mathbf{1} 4}$ Their effectiveness is based on a combination of ligands with complementary donor and acceptor properties: on the one hand, a carbene ligand capable of acting as both a strong electron donor and effective $\pi$-acceptor, and, on the other hand, an anionic ligand $\mathrm{X}$ that on photochemical or electrical excitation enables charge transfer to the acceptor orbital of the carbene. Cyclic (alkyl)(amino)carbene (CAAC) ligand $s^{5-9}$ were found to be particularly suitable on the basis of their balance between donor and acceptor properties. ${ }^{\mathbf{1 0}} \mathrm{CAAC}$

${ }^{a}$ School of Chemistry, University of East Anglia, Norwich Research Park, Norwich, NR4 7TJ, UK.E-mail: A.Romanov@uea.ac.uk; m.bochmann@uea.ac.uk

${ }^{b}$ Department of Physics, Cavendish Laboratory, Cambridge University, Cambridge CB3 oHF, UK.E-mail:djnc3@cam.ac.uk

'Department of Chemistry, University of Eastern Finland, Joensuu Campus, FI-80101 Joensuu, Finland. E-mail: mikko.linnolahti@uef.fi

$\dagger$ Electronic supplementary information (ESI) available: Detailed experimental procedures, single-crystal X-ray diffraction data, photophysical and OLED device characterization, and computational details. CCDC 1912300 for Au1 (Monoclinic), 1912299 for Au2, 1911240 for Au4, 1911241 for Au5, 1911239 for Au6, 1911237 for Au7, 1911238 for Au8 contains the supplementary crystallographic data for this paper. For ESI and crystallographic data in CIF or other electronic format see DOI: 10.1039/c9sc04589a complexes of copper, ${ }^{1}$ silver $^{11}$ and gold ${ }^{1,7,12}$ are thermally very stable and resistant to ligand rearrangements. Even simple CAAC copper halide adducts give photoluminescence quantum yields (PLQY) as high as 96\%. ${ }^{1}$ Combining CAAC carbene ligands with anions $\mathrm{X}=$ arylamide and especially carbazolate proved a particularly effective design strategy for bright phosphors, to give "carbene-metal-amides" (CMAs). The incorporation of such CMA-type copper and gold complexes into the emissive layer of organic light-emitting diodes (OLEDs) enabled the construction of devices with near-100\% internal and $>25 \%$ external quantum efficiency (EQE) by both solution-processing and thermal vapor deposition techniques. ${ }^{13,14}$ OLEDs based on mononuclear silver complexes as emitters were obtained similarly. ${ }^{15}$

The emission mechanism of CMAs has been the subject of several theoretical and spectroscopic investigations. ${ }^{16-19}$ Theoretical calculations revealed that the highest occupied molecular orbital (HOMO) is located mostly on the carbazole, while the lowest unoccupied molecular orbital (LUMO) comprises mainly the $\mathrm{C}_{\text {carbene }}$ p-orbital. ${ }^{\mathbf{1 3}, 15}$ Excitation is a ligand-to-ligand charge transfer process (LLCT) from the carbazole to the carbene ligand involving mainly a HOMO $\rightarrow$ LUMO transition, with only a minor ( $\leq 5 \%$ to HOMO, $7-15 \%$ to LUMO) contribution of the metal orbitals. For gold carbazolate complexes we reported earlier that inter-system crossing to triplets occurs within 4 ps after photoexcitation. ${ }^{13}$ The emission process from CMAs is associated with strong dipole moment changes 
between ground $\left(\mu_{\mathrm{gs}}\right)$ and excited states $\left(\mu_{\mathrm{es}}\right)$ (Scheme 1$)$. This process differs therefore from that operative in most metalbased phosphors where metal-to-ligand charge transfer (MLCT) is dominant. ${ }^{20-28}$

The emissions from CMA complexes appear to follow predominantly a thermally activated delayed-fluorescence (TADF) mechanism. However, whereas the classical TADF process shows a characteristic blue-shift on warming, ${ }^{21-24}$ CMAs display a temperature-dependent red-shift. Current models suggest that given the rotational flexibility of linear L-M-X complexes, intramolecular twisting of the carbene relative to the amide ligand planes affects both the ground and excited state energy levels. The exchange energy, $\Delta E_{\mathrm{ST}}$, is small and at high twist angles approaches zero. ${ }^{14-18}$ This enables efficient mixing of singlet and triplet excited states and results in short (sub-microsecond to microsecond) excited state lifetimes. Radiative rates exceeding $10^{6} \mathrm{~s}^{-1}$ and near unity PLQY values have been realized. ${ }^{13-15}$ The principle of carbene-metal-amide photoemitters has recently been extended to dendritic systems ${ }^{29}$ and to a range of related carbazolate-based CMA systems. ${ }^{30-32}$

Whereas the studies so far have concentrated on the carbazole ligands, where the amide $\mathrm{N}$-atom is locked into a rigid 5membered ring, we report here a series of CMA complexes carrying amide ligands based on various phenoxazine, phenothiazine, di- and tribenzazepine and sulfone derivatives in which the N-atoms are part of conformationally flexible 6- or 7membered rings. The electron-donor capacity of these amido ligands varies significantly, so that the luminescence wavelengths can be tuned to cover the visible spectrum from blue to deep red. ${ }^{33}$ We report the use of these emitters in OLEDs, including the first case of a device based on a mechanochromic CMA material, an application enabled by the conformational flexibility of the amide ligand.

\section{Results and Discussion}

\section{Synthesis and structure}

Copper and gold CMA complexes of adamantyl-substituted CAAC ligands $\left({ }^{\mathrm{Ad}} \mathrm{L}\right)$ were prepared in high yields as shown in

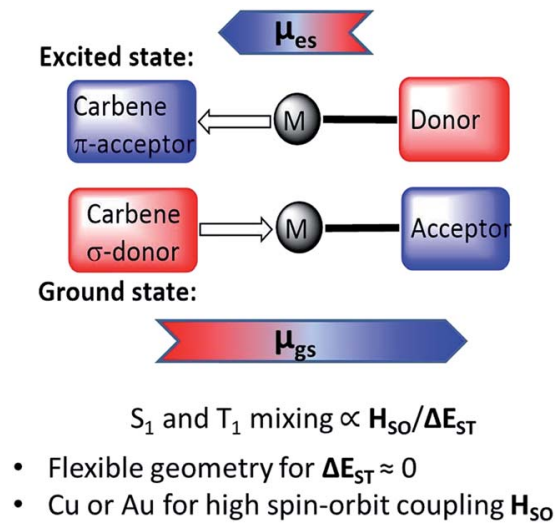

Scheme 1 Principle of the CMA structure in the ground and excited states, with arrows indicating direction of molecular ground state $\left(\mu_{\mathrm{gs}}\right)$ and excited state dipoles $\left(\mu_{\mathrm{es}}\right)$.

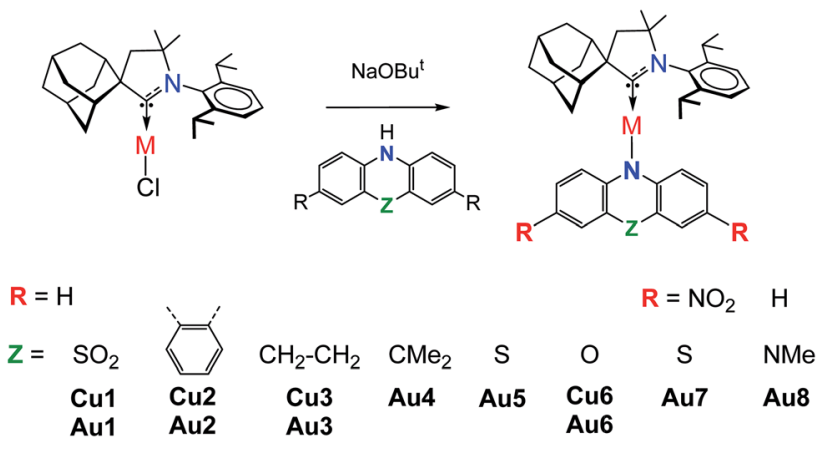

Scheme 2 Synthesis and structures of carbene metal amide complexes.

Scheme 2, following previously established procedures. ${ }^{2,12,13}$ The color of the complexes in the solid state or in solutions varies significantly and depends on the donor strength of the amide ligand (colorless Au1, yellow Au2-Au4, orange Au5, red Au6 and deep-purple Au7/Au8; the copper analogues show very similar colors). The complexes possess good solubility in aromatic and polar non-protic solvents like dichloromethane, THF, and acetone, and moderate solubility in acetonitrile. Gold CMA complexes are stable in air for several months and indefinitely stable under argon. The stability of the copper complexes is reduced to several hours in air as the electron donor strength of the amide ligand increases. According to thermogravimetric analysis (TGA, under nitrogen) the decomposition temperature $\left(T_{\mathrm{d}}\right)$ for gold complexes is $15-30{ }^{\circ} \mathrm{C}$ higher than for copper compounds (see ESI, Fig. S1 $\dagger$ ). In the series of gold complexes Au1-Au8 thermal stability decreases with increasing electron donor properties of the amide ligand, for instance, $T_{\mathrm{d}}$ is $322{ }^{\circ} \mathrm{C}$ for Au1 vs. $250{ }^{\circ} \mathrm{C}$ for Au8.

Crystals of the copper and gold complexes suitable for X-ray diffraction were obtained by layering of $\mathrm{CH}_{2} \mathrm{Cl}_{2}$ or toluene solutions with hexane. Key structural parameters for the crystal structures are defined in Fig. 1 and collected in Table 1. The crystal structures are shown in Fig. S2 (see ESI). $\dagger$

All compounds are monomeric, with the molecules arranged into three-dimensional networks by weak $\mathrm{C}-\mathrm{H} \cdots \mathrm{X}$ hydrogen bonds $(\mathrm{X}=\mathrm{Cl}, \mathrm{O}, \mathrm{N}$, and $\mathrm{S})$. There are no close metal-metal contacts. Complexes with six-membered amide ligands (Au1, Au4-Au8) exhibit $\mathrm{C}(1)_{\mathrm{CAAC}}-\mathrm{Au}$ bond lengths that are very similar to the carbazolate complex ( $\left.{ }^{\mathrm{Ad}} \mathrm{CAAC}\right) \mathrm{Au}($ carbazolate) (CMA1), while the $\mathrm{Au}-\mathrm{N}(2)$ bond lengths are longer by 0.01-0.03 $\mathrm{A}$ (Table 1). The carbene-carbon $\mathrm{C}(1)$ lies in the $\mathrm{N}(1)-\mathrm{Au}-\mathrm{C}(2)$ plane for all complexes. The amide $\mathrm{N}$-atom $\mathrm{N}(2)$ can tend towards a pyramidal geometry (deviation from the M1 $\cdots \mathrm{C} 28 \cdots \mathrm{C} 39$ plane), as found in phenothiazine-based Au1, Au5, Au7, and in the oxazine Au6 complexes (Fig. S1 $\dagger$ ).

Complex Au2, which bears a seven-membered amide, shows both $\mathrm{C}(1)_{\mathrm{CAAC}}-\mathrm{Au}$ and $\mathrm{Au}-\mathrm{N}(2)$ bond lengths shorter by $0.01 \AA$ than CMA1. Such deviations in bond lengths lead to the $\mathrm{C}(1)_{\mathrm{CAAC}} \cdots \mathrm{N}(2)$ distance being longer for six-membered amide complexes (0.01-0.04 $\AA$ ) and shorter by $0.03 \AA$ for Au2 compared with CMA1 (4.117 $\AA$, see Table 1$)$. The shortest $\mathrm{C}(1)_{\mathrm{CAAC}} \cdots \mathrm{N}(2)$ 


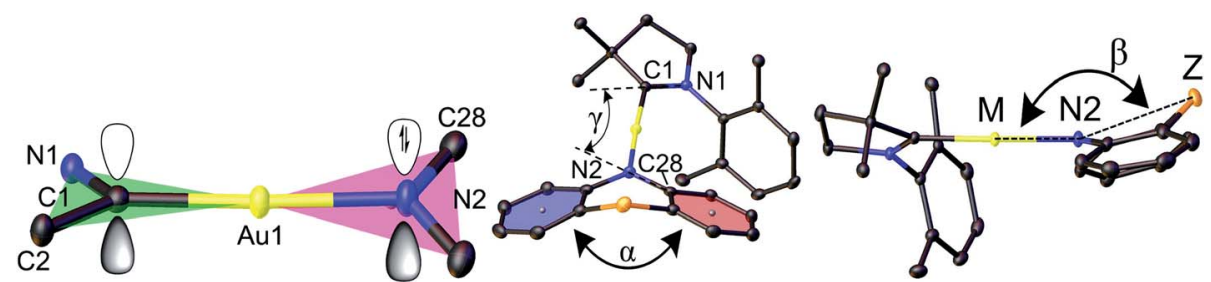

Fig. 1 Structural definitions of the dihedral (butterfly) angle $\alpha$ between the two best planes of the aromatic 6-rings and deviation of the bridgehead (Z) from the linear CMA unit, angle $\beta$.

distance for complex Au2 is accompanied by significant deviation from linear geometry around gold atom and shows the smallest $\mathrm{C}(1)-\mathrm{Au}-\mathrm{N}(2)$ angle $\left(172.4(1)^{\circ}\right)$ in the gold series. The distance between donor and acceptor (C1 $\cdots$ N2) plays an important role in the charge transfer step and, together with the carbene/amide twist angle, can be used as a molecular design tool to control the HOMO-LUMO overlap.

The six- and seven-membered amide ligands in Au1 to Au8 are non-planar ("butterfly" conformation) and conformationally flexible. To evaluate the deviations from planarity we introduce the folding angle $\alpha$ as the angle between best planes through the two benzo-rings of the amide ligand (Fig. 1). The angle $\beta$ is defined as the angle between the $\mathrm{M}-\mathrm{N}(2)$ vector and $\mathrm{Z}$, where $\mathrm{Z}$ is a bridgehead or the centroid of the C34-C39 bond of Au2, see Fig. 1. Complex Au4 exhibits the largest angle $\alpha$ and displays an almost planar geometry of the amide ligand $\left(\mathrm{Z}=\mathrm{CMe}_{2}\right)$. A bent geometry with smaller $\alpha$ angles $\left(154-167^{\circ}\right)$ has been found for $\mathrm{Z}$ $=\mathrm{S}, \mathrm{SO}_{2}$, NMe (Table 1), while the smallest values of $\alpha$ and $\beta$ are found for Au2 due to the sterically demanding $o$-phenylene bridge.

Crystals of Au1 were obtained in two forms, a monoclinic and an orthorhombic phase. Monoclinic crystals were grown by layering a dichloromethane solution with hexane and are obtained as the solvate, Au1 $\cdot 0.5 \mathrm{CH}_{2} \mathrm{Cl}_{2}$. They contain two independent Au1 molecules in the unit cell, which differ by $10^{\circ}$ in the $\beta$ angle, indicating the flexibility of the sulfone bridge in sixmembered amide $v s$. the rigid five membered carbazolate ligand in CMA1 (Fig. S3†). Layering a toluene solution of Au1 with hexane leads to orthorhombic phase which exhibits a more flattened conformation of the amide ligand $(\alpha / \beta=159.7(3) /$ $164.6(6)^{\circ}$ for the orthorhombic vs. 154.5(1)/153.7(2) ${ }^{\circ}$ for the monoclinic form, Table 1). These structural variations appear to exercise a strong influence on the photo- and electroluminescence properties of Au1 (vide infra). Unfortunately, systematic twining prevents a detailed discussion of bond lengths and angles of the orthorhombic Au1 complex.

\section{Electrochemistry}

Cyclic voltammetry (CV) was used to analyze the redox behavior of the new copper and gold complexes in MeCN solution, using $\left[{ }^{n} \mathrm{Bu}_{4} \mathrm{~N}\right] \mathrm{PF}_{6}$ as the supporting electrolyte (Table S1, and ESI, Fig. S4-S10 $\dagger$ ). All gold complexes show a quasi-reversible, carbene ligand-centered reduction process similar to our previous reports. ${ }^{2,13,29}$ The peak-to-peak separation $\Delta E_{\mathrm{p}}$ varies within a small range of 77-91 $\mathrm{mV}$ for gold complexes; this is higher than the expected value of $59 \mathrm{mV}$ for a theoretical reversible one-electron process. The oxazine complex Cu6 shows quasireversible reduction with a peak-to-peak separation $\Delta E_{\mathrm{p}}$ of $79 \mathrm{mV}$, whereas other copper complexes Cu1-Cu3 showed irreversible reduction processes. The lowest reduction potential was found for $\mathbf{M 1}(\mathbf{M}=\mathrm{Cu}$ and $\mathrm{Au})$ and $\mathbf{A u} 7$ due to the strongly electron-withdrawing nature of the $\mathrm{SO}_{2}$ and $\mathrm{NO}_{2}$ groups, which results in a stabilization of the LUMO by $0.2 \mathrm{eV}$ for $\mathbf{M 1}$ and $1 \mathrm{eV}$ for Au7, respectively (Fig. 2). Unlike $\mathbf{M 1}$ and Au7, the reduction potentials of all other complexes are largely insensitive to the nature of the amide ligands and show very similar LUMO energy levels (Table S1, $\uparrow$ Fig. 2). Such a marked difference in a first reduction potential for complex Au7 indicates that it is likely localized on the amide ligand rather than on the carbene (see Fig. S9 in ESI $\dagger$ ).

The copper and gold complexes Cu1-Cu3 and Au1-Au4 undergo multiple irreversible amide ligand-centered oxidation processes at all scan rates. The phenothiazine-based (Au5 and Au7), oxazine (Cu6 and Au6) and $N$-methylphenazine (Au8)

Table 1 Selected bond lengths $[\AA \AA]$ and angles $\left[^{\circ}\right]$ of copper and gold amide complexes. The values for the monoclinic form of Au1 are the average for the two independent molecules in the unit cell

\begin{tabular}{|c|c|c|c|c|c|c|c|}
\hline & M-C1, (A) & M-N2, (̊) & $\mathrm{C} 1 \cdots \mathrm{N} 2,(\AA)$ & Angle, $\left({ }^{\circ}\right) \mathrm{C} 1-\mathrm{M}-\mathrm{N} 2$ & $\begin{array}{l}\text { Torsion angle, } \\
\text { ( }) \text { N1-C1-N2-C28 }^{\circ} \text { - }\end{array}$ & $\begin{array}{l}\text { N2 deviation from } \\
\text { M1 } \cdots \mathrm{C} 28 \cdots \mathrm{C} 39,(\AA)\end{array}$ & Angles, $\left({ }^{\circ}\right) \alpha / \beta$ \\
\hline Au1 & $1.994(6)$ & $2.055(5)$ & $4.049(6)$ & $176.5(2)$ & $17.4(5)$ & $0.037(6)$ & $154.5(1) / 153.7(2)$ \\
\hline Au4 & $1.984(4)$ & $2.053(3)$ & $4.037(4)$ & $178.73(14)$ & $16.6(5)$ & $0.005(4)$ & $174.8(1) / 173.6(1)$ \\
\hline Au5 & $1.983(2)$ & $2.043(2)$ & $4.026(2)$ & $177.05(8)$ & $12.9(4)$ & $0.098(2)$ & $144.8(2) / 160.3(1)$ \\
\hline Au6 & $1.989(6)$ & $2.033(6)$ & $4.021(6)$ & $176.5(3)$ & 21.1(4) & $0.070(7)$ & $167.6(2) / 160.5(3)$ \\
\hline
\end{tabular}




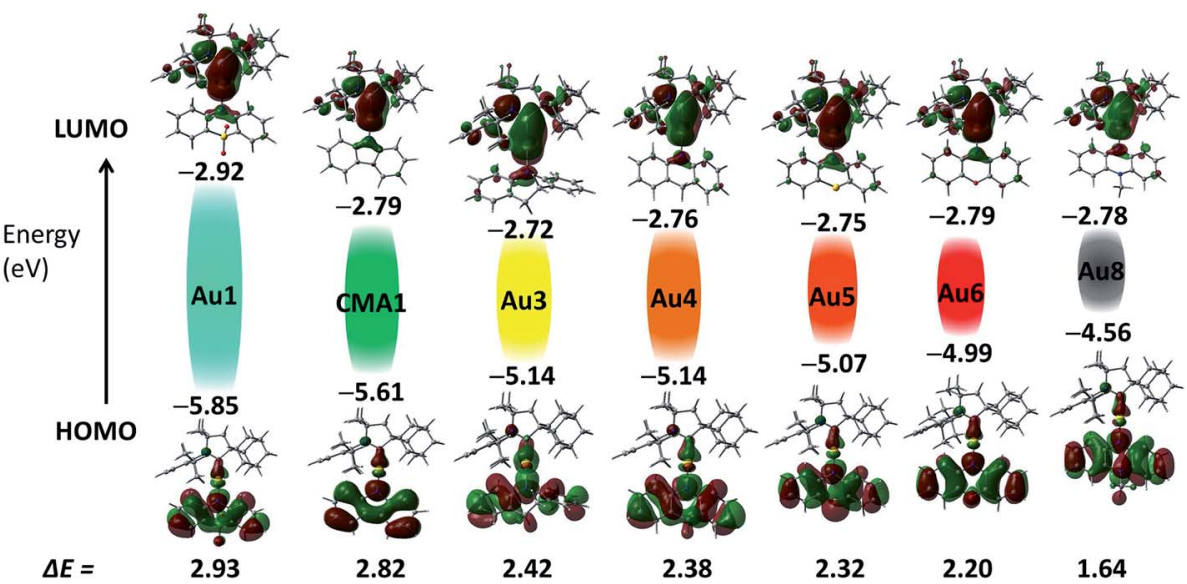

Fig. 2 Shapes and energies of HOMOs and LUMOs involved in the vertical excitation $\left(S_{0} \rightarrow S_{1}\right)$ of gold complexes Au1-Au8, in comparison with the carbazolate complex CMA1. ${ }^{13}$ The $E_{\mathrm{HOMO}} / E_{\mathrm{LUMO}}(\mathrm{eV})$ and band gap values $(\Delta E, \mathrm{eV})$ were obtained by cyclic voltammetry.

show multiple and quasi-reversible oxidation waves with a welldefined back-peak (see ESI, Fig. S5 and S6 $\dagger$ ). The first quasireversible oxidation process shows a peak-to-peak separation $\Delta E_{\mathrm{p}}$ in the range 66-84 $\mathrm{mV}$ for copper and gold compounds, whereas larger variations in $\Delta E_{\mathrm{p}}$ values (59-106 mV) were observed for the second or third quasi-reversible processes (Table S1†). The quasi-reversibility of the reduction and oxidation peaks is witnessed by a small shift of $10-20 \mathrm{mV}$ in the peak position $E_{\mathrm{p}}$ on increasing the scan rate and the peak-to-peak separation $\Delta E_{\mathrm{p}}$ of $77-91 \mathrm{mV}$ (at $100 \mathrm{mV} \mathrm{s}^{-1}$ ), which is close to the ideal value of $59 \mathrm{mV}$ for a one-electron reversible couple. For instance, complex Au1 shows an increase of the $i_{\mathrm{pa}} / i_{\mathrm{pc}}$ ratio for the reduction process from 0.74 (at $0.05 \mathrm{~V} \mathrm{~s}^{-1}$ ) towards unity $\left(0.85\right.$ at $\left.2 \mathrm{~V} \mathrm{~s}^{-1}\right)$ which is the ideal value for a reversible couple (Fig. S5, see ESI $\dagger$ for a varied scan rate study for gold and copper complexes showing quasi-reversible redox processes).

On the basis of the electrochemistry data of the free amine ligand $\mathrm{s}^{34}$ and theoretical calculations all oxidation waves can be assigned to amide-centered processes. The band gap value $(\Delta E, \mathrm{eV}$ see Table $\mathrm{S} 1 \dagger)$ decreases in the series Au1-Au8 from $2.93 \mathrm{eV}$ for Au1 to $1.64 \mathrm{~V}$ for Au8 as a result of the decrease in the first oxidation potential and destabilization of the HOMO energy from $-5.85 \mathrm{eV}$ for Au1 to $-4.56 \mathrm{eV}$ for Au8.$^{35}$ Such trends are in line with the increasing electron-donor strength of the amide ligand. The exception is complex Au7 which shows a small band gap value of $1.9 \mathrm{eV}$ since in this case both reduction and oxidation processes are centered on the amide ligand, as can be seen by comparison with the free amine ligand 10- $\mathrm{H}^{-}$ 3,7-dinitrophenothiazine (Fig. S9 in ESI†े).

\section{Computational results}

The electronic structure of copper and gold complexes was investigated by density-functional theory (DFT) for the ground state and time-dependent DFT (TD-DFT) ${ }^{36}$ calculations for the excited states, using the MN15 functional by Truhlar $^{37}$ in combination with def2-TZVP basis set by Ahlrichs. ${ }^{38-40}$ For complexes where $\mathrm{X}=\mathrm{SO}_{2}$, or $\mathrm{S}\left(\mathrm{R}=\mathrm{NO}_{2}\right)$ the optimized structures for the $S_{1}$ and $T_{1}$ excited states show twist angles between
CAAC carbene and amide ligand planes of only $20^{\circ}$. Excitation of the molecules is accompanied by a flattening of the six- or seven-amide ligands; the $\alpha / \beta$ angles are larger by $5-10^{\circ}$ compared with the ground state geometries determined by $\mathrm{X}$ ray diffraction.

The LUMO is aligned along the metal-carbene bond, whereas the HOMO is localized on the amide ligand. The contribution of the metal orbitals is $\approx 3-5 \%$ for the HOMO and $7-16 \%$ for the LUMO (ESI, Table S3 $\%$ ). The calculated HOMOLUMO energy gaps are consistent the values obtained by electrochemistry for copper and gold complexes (Fig. 2 and Table $\mathrm{S} 4 \uparrow$ ). The charge transfer process is predominantly HOMO $\rightarrow$ LUMO in character (>96\%). The copper and gold complexes are characterized by small exchange energies $\Delta E_{\mathrm{ST}}$ of $<0.3 \mathrm{eV}$ (Table S5†).

All molecules possess a high ground state dipole moment $\left(\mu_{\mathrm{gs}}\right)$ in the range of 8-17 D (see ESI, Table S6 $\dagger$ ) oriented along the metal- $\mathrm{C}_{\text {carbene }}$ vector. The dipole moments in the excited states $\left(\mu_{\mathrm{es}}\right)$ are 1-4 D and in most cases changes direction, commensurate with significant charge transfer from the amide to the carbene ligand.

The exception to this is Au7 where an intraligand HOMO $\rightarrow$ LUMO+1 charge transfer (ILCT) process for the amide ligand dominates, while the contribution by the $\mathrm{HOMO}($ amide) $\rightarrow$ LUMO(carbene) transition is low (see ESI, Table S5, $\dagger$ ). Au7 possesses the highest oscillator strength $(f=0.2634)$ and by far the largest exchange energy $\Delta E_{\mathrm{ST}}$ of $>0.5 \mathrm{eV}$, indicative of a potential competing mechanism of ligand-based fluorescence. In agreement with this analysis, Au7 shows no change in dipole moment since the $S_{0} \rightarrow S_{1}$ transition is localized on the amide ligand. Evidently, the nitro substituents outcompete the carbene as $\pi$-acceptors and stabilize local excited states.

\section{Photophysical properties}

The UV/vis absorption spectra for copper and gold complexes in THF solution (Fig. 3 and S11†) show strong $\pi-\pi^{*}$ transitions at ca. $270 \mathrm{~nm}$ ascribed to an intra-ligand (IL) transition of the CAAC carbene. The broad low energy absorption band for 

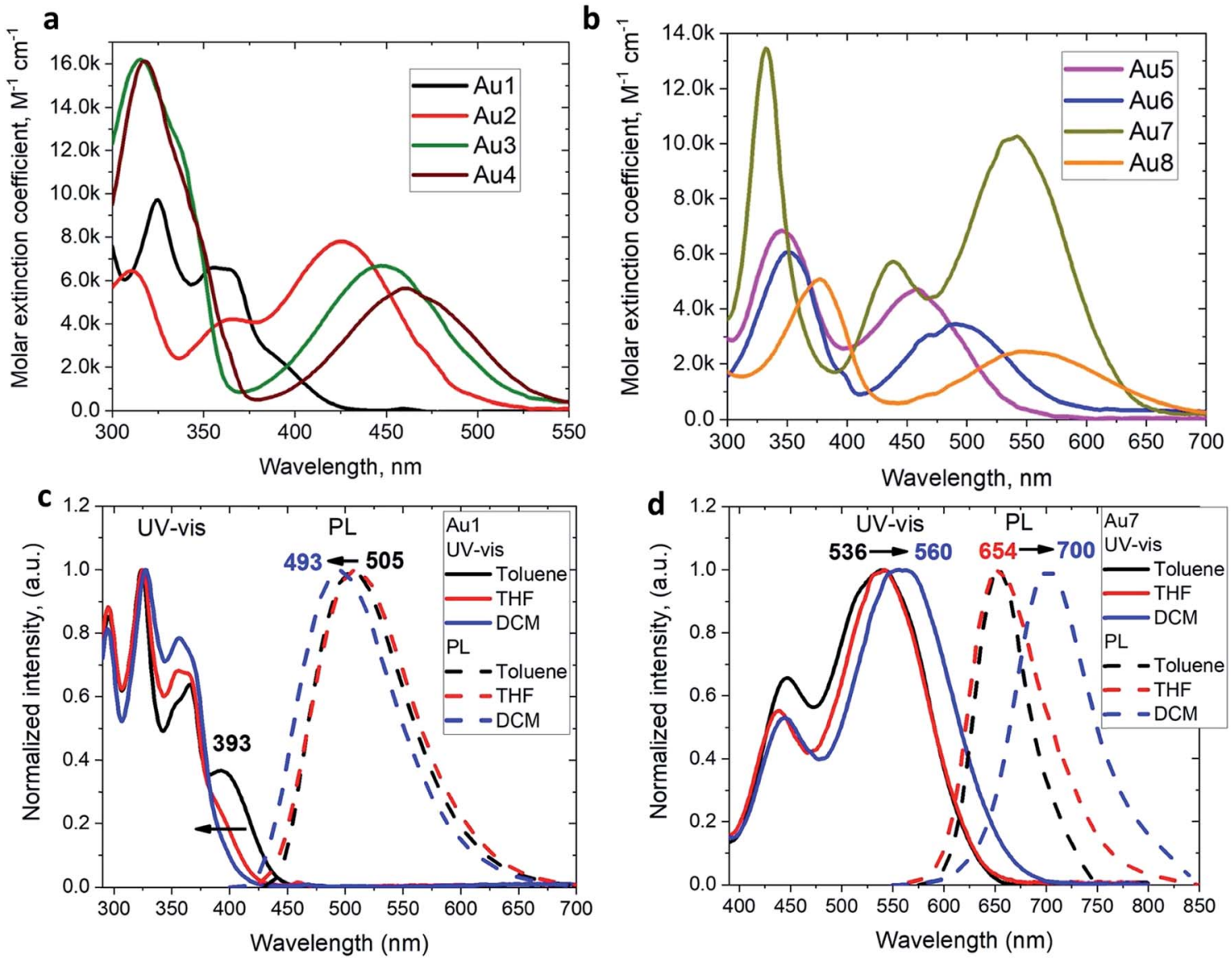

Fig. 3 UV/vis spectra of gold Au1-Au4 (a) and Au5-Au8 (b) complexes in THF solution (298 K). Normalized UV-vis and emission spectra in toluene, THF and $\mathrm{CH}_{2} \mathrm{Cl}_{2}$ for gold complex Au1 (c) and $\mathrm{Au} 7$ (d) showing negative and positive solvatochromism, respectively.

copper and gold complexes from $c a .380$ to $560 \mathrm{~nm}$ is assigned to ligand-to-ligand charge transfer $\mathrm{L}(\mathrm{M}) \mathrm{LCT}\{\pi($ carbazole)$\left.\pi^{*}(\mathrm{CAAC})\right\}$, with a minor contribution of the metal orbitals according to the DFT calculations. The absorption onset of the CT band and peak position shows a red-shift of over $9600 \mathrm{~cm}^{-1}$ $(c a .175 \mathrm{~nm})$ for the gold series of complexes; this trend follows the increase in electron-donor character of the amide ligands and is largely consistent with the decrease in the band gap values $(\Delta E$, Table $\mathrm{S} 1 \dagger)$ identified by cyclic voltammetry (vide supra). The molar extinction coefficients of the copper complexes are 2-3 times lower than those of their gold analogues, in line with the theoretically calculated trend in oscillator strength (see ESI Table S5 $\dagger$ ). The molar extinction coefficients $(\varepsilon)$ of the L(M)LCT for gold complexes decrease from $\varepsilon=7800$ for Au2 to $2500 \mathrm{M}^{-1} \mathrm{~cm}^{-1}$ for Au8 in THF solution. Au7 is the exception and shows the highest value of $\varepsilon=$ $10260 \mathrm{M}^{-1} \mathrm{~cm}^{-1}$ due to the dominant contribution of the amide IL $\pi-\pi^{*}$ transition.

The photoluminescence (PL) properties of copper and gold complexes were investigated in toluene solution at $298 \mathrm{~K}$, in frozen 2-methyltetrahydrofuran (MeTHF) at $77 \mathrm{~K}$, as a 5 weight-\% dopant in a polystyrene (PS) matrix, and as neat films under $\mathrm{N}_{2}$ (Fig. 4; see Fig. $\mathrm{S} 11$ and $\mathrm{S} 13 \dagger$ for copper complexes). The PL data are summarized in Table 2 . The complexes exhibit broad intramolecular charge transfer emission profiles with FWHM (full-width half-maximum) values of $65-120 \mathrm{~nm}$. The emission colors range from skyblue to deep-red/near-IR. In a polystyrene matrix, where molecular flexibility is restricted, emissions are slightly blueshifted relative to the PL in toluene solution, and in the series of gold complexes Au1-Au7 the PL quantum yields (PLQYs) decrease from 83 to $8 \%$ as the wavelength increases. The luminescence of all complexes is reversibly quenched by $\mathrm{O}_{2}$. The emission profiles red-shift following the band gap values $(\Delta E$, Table $\mathrm{S} 1 \dagger)$, e.g. for the gold complexes in the sequence from Au1 to Au8. The basicity of the amine can be correlated with the emission properties of the CMA materials. For instance, the flexible amine ligand $10 H$-phenothiazine 5,5dioxide $\left(\mathrm{p} K_{\mathrm{a}}=15.7\right),{ }^{41}$ which incorporates a strongly electronwithdrawing linker $\left(\mathrm{Z}=\mathrm{SO}_{2}\right)$, reduces the basicity compared with carbazole $\left(\mathrm{p} K_{\mathrm{a}}=19.9\right)$, resulting in sky-blue luminescence for Au1 vs. green for CMA1. On the other hand, more basic amines with $\mathrm{Z}=o$-phenylene $\left(\mathrm{p} K_{\mathrm{a}}=26.1\right)$, ethylene $\left(\mathrm{p} K_{\mathrm{a}}\right.$ $=25.5), \mathrm{S}\left(\mathrm{p} K_{\mathrm{a}}=22.7\right)$ or $\mathrm{O}\left(\mathrm{p} K_{\mathrm{a}}=21.6\right)^{41}$ produce either yellow or orange/red emitters Au2-Au6 and Au8. However, since there is a complicated simultaneous interplay between the structural and electronic factors, the emission colours cannot be predicted solely on the amine basicity. For instance, the 

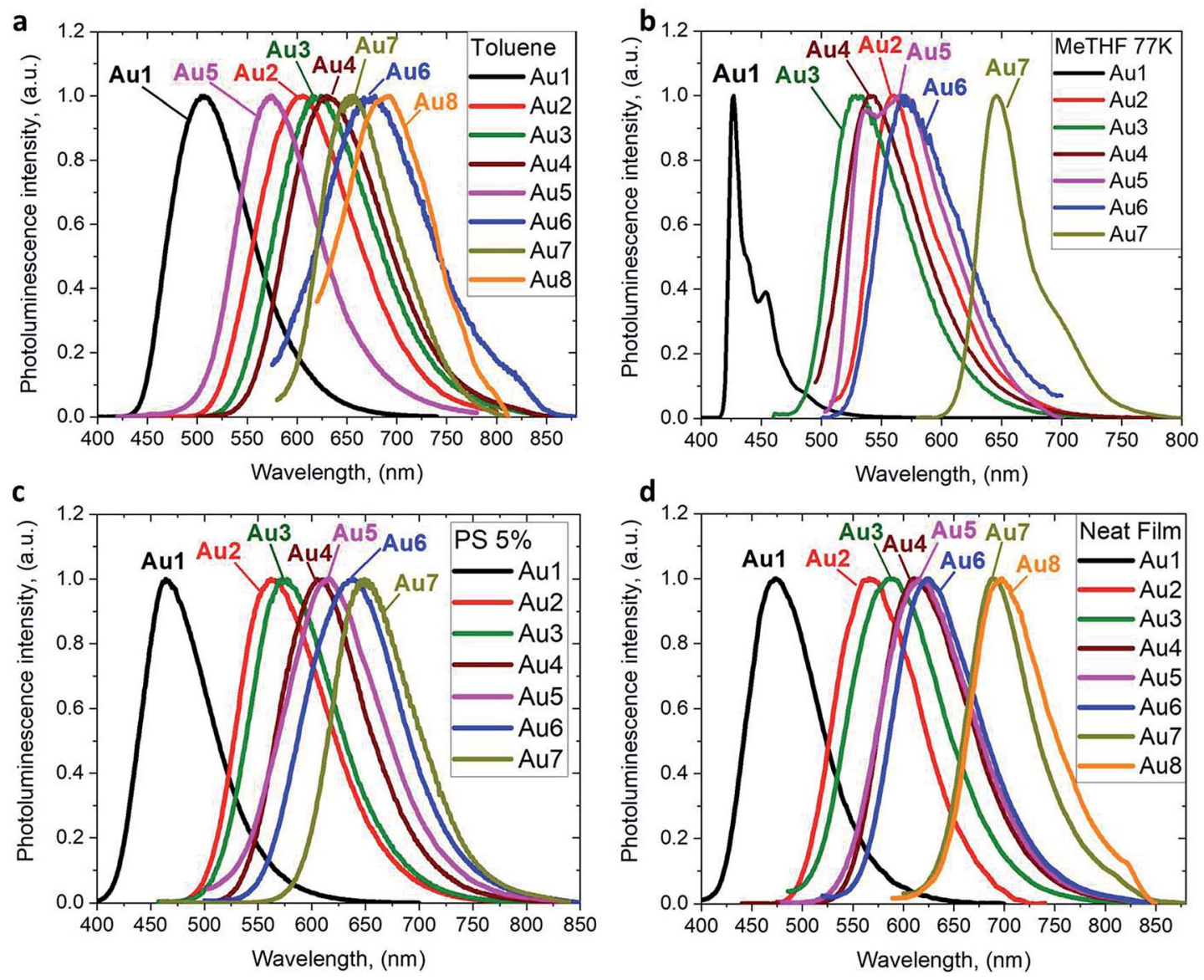

Fig. 4 PL spectra of gold CMA complexes Au1-Au8 in toluene solution at $298 \mathrm{~K}$ (a), in MeTHF at $77 \mathrm{~K}$ (b), as a 5 wt\% dopant in polystyrene (c), and as neat films under $\mathrm{N}_{2}$ (d).

amines used for complexes Au2-Au4 have similar $\mathrm{p} K_{\mathrm{a}}$ values but the emission profile red-shifts by $c a$. 10-20 nm from yellow (Au2) to yellow-orange (Au3) to orange (Au4). This can be rationalized by difference in amide geometry, where the rigid linker $\mathrm{Z}=o$-phenylene (Au2) leads to the most acute butterfly angles $(\alpha / \beta)$, whereas Au4 shows an almost flat amide ligand $\left(\alpha / \beta\right.$ ca. $\left.180^{\circ}\right)$. The same trend is clear when linkers $\mathrm{Z}$ are heteroatoms with comparable rigidity: yellow-orange $\operatorname{Au} 5(\mathrm{Z}=$ S) show a butterfly angle $\alpha$ which is $20^{\circ}$ more acute than in orange-red Au6 $(\mathrm{Z}=\mathrm{O})$. If $\mathrm{Z}=\mathrm{NMe}$ this trend can be extended into the near-IR range, as in complex Au8.

The 3,7-dinitrophenothiazine compound $\mathbf{A u} 7$ is an exception in the series: the LUMO contains a significant contribution of the amide ligand, while the LUMO+1 is entirely located on the amide ligand (see ESI, Tables S2 and $\mathrm{S} 4 \dagger$ ). As a result excitation of Au7 leads to intra-ligand HOMO $\rightarrow$ LUMO+1 transition without flipping of the transition dipole moment value (Table $\mathrm{S} 6 \dagger$ ). This is supported by positive solvatochromic behavior in the UV-vis and photoluminescence spectra in solvents of different polarities (see Fig. 3). Au7 differs therefore markedly from the other gold complexes (see Fig. 3 for Au1 and Fig S15 $\dagger$ for Au2-Au4) which show a negative solvatochromism due to the flipping of the transition dipole moments between ground and excited states (Table S6 $\dagger$ ).
The emission spectra were measured in frozen 2-MeTHF solution to identify the energy of the local excited triplet ${ }^{3} \mathrm{LE}$ state. All complexes exhibit a significant blue-shift upon cooling to $77 \mathrm{~K}$ (Fig. 4b). Complexes Cu1 and Au1 show well-structured emission profiles originating from the ${ }^{3} \mathrm{LE}$ state of the amide ligand. Complexes M2-M6 $(\mathrm{M}=\mathrm{Cu}, \mathrm{Au})$ show only blue-shifted broad CT emissions (see Fig. 4b) upon cooling, which preclude identification of the ${ }^{3} \mathrm{LE}$ energy and the $\Delta E\left({ }^{1} \mathrm{CT}-{ }^{3} \mathrm{LE}\right)$ energy gap values. A similar behavior has recently been reported for copper carbazolate complexes with mono- and diamidocarbene ligands. ${ }^{31}$ Unlike M1-M6, the emission profile for $\mathbf{A u 7}$ is not shifted upon cooling MeTHF solution from 298 to $77 \mathrm{~K}$ and gives a similar peak maximum at $649 \mathrm{~nm}$, with a narrower emission profile at $77 \mathrm{~K}$ and a shoulder at the lower wavelength (Fig. 4).

The PLQY values decrease generally from M1 to M8 in all media, with a few exceptions. For instance, in PS matrix complexes Au3 has a higher PLQY than Au2, whereas in toluene solution the PLQY of Au3 is one order lower than that of Au2. The excited state lifetimes of Au2 are 2-4 times shorter than for Au3. This behavior is likely a reflection of the relative rigidity of the tribenzoazepine ligand $(\mathrm{Z}=o$-phenylene) compared with the rather flexible 10,11-dihydrobenzazepine ring $(\mathrm{Z}=$ ethylene, vide supra). The gold complexes Au1-Au6 show short excited 
Table 2 Photophysical properties of copper and gold complexes as neat films, in toluene solution and in polystyrene (PS) matrix at 5 weight-\%

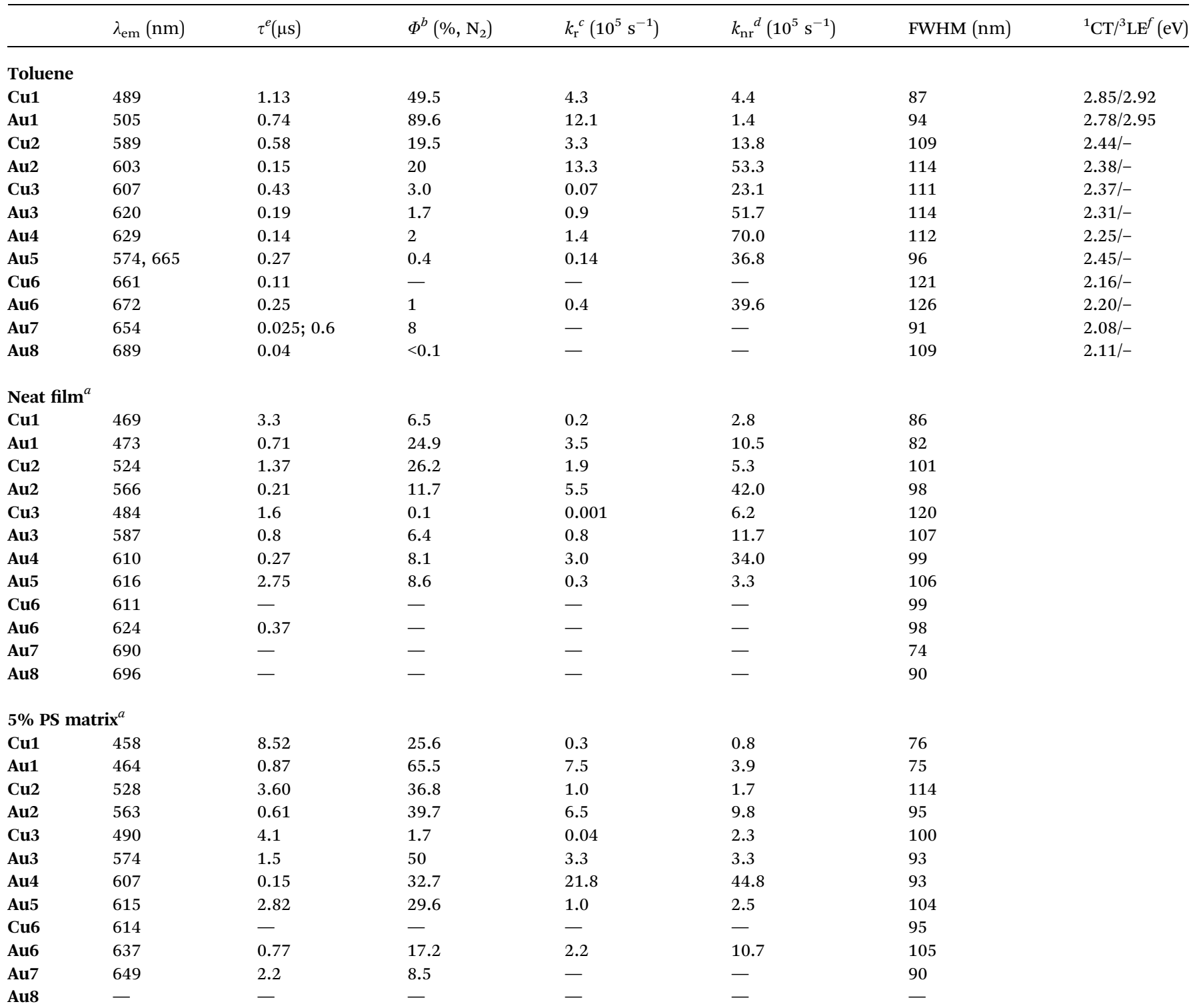

${ }^{a}$ Films (neat and in PS host) were prepared by drop-casting from chlorobenzene solutions $\left(10 \mathrm{mg} \mathrm{mL}{ }^{-1}\right)$ onto a hot quartz substrate and annealed for 5 min. ${ }^{b}$ Quantum yields determined using an integrating sphere. ${ }^{c}$ radiative rate constant $k_{\mathrm{r}}=\Phi / \tau .{ }^{d}$ Nonradiative constant $k_{\mathrm{nr}}=(1-\Phi) / \tau$. ${ }^{e}$ In case of two-component lifetime $\tau$ an average was used: $\tau_{\mathrm{av}}=\left(B_{1} /\left(B_{1}+B_{2}\right)\right) \tau_{1}+\left(B_{2} /\left(B_{1}+B_{2}\right)\right) \tau_{2}$, where $B_{1}$ and $B_{2}$ are the relative amplitudes for $\tau_{1}$ and $\tau_{2}$, respectively. ${ }^{f 1} \mathrm{CT}$ and ${ }^{3} \mathrm{LE}$ energy levels based on the onset values of the emission spectra blue edge in MeTHF glasses at $77 \mathrm{~K}$ and in toluene solutions at $298 \mathrm{~K}$.

state lifetimes of the order of $0.2-2.8 \mu \mathrm{s}$ in PS and $0.1-0.7 \mu \mathrm{s}$ in toluene at $298 \mathrm{~K}$, leading to radiative rate constants $k_{\mathrm{r}}$ of $10^{4}$ to $10^{6} \mathrm{~s}^{-1}$. The non radiative rate constants $k_{n \mathrm{r}}$ increase up to 40 times from M1 to M4/6 in line with the decreasing band gaps, which is consistent with the energy gap law. ${ }^{42}$

Copper complexes are generally less emissive than their gold analogues, with the highest PLQY being displayed by Cu1 (49.5\% in toluene). The lower PLQY values for the copper complexes correlates well with the lower oscillator strength coefficients for $\mathrm{S}_{1} \rightarrow \mathrm{S}_{0}$ transition and smaller contribution of the metal orbitals into LUMO compared with the analogous gold complexes (see ESI, Tables S3 and S5 $\dagger$ ). The copper analogues show excited state lifetime values that are up to three times longer than for the gold analogs (Table 2). The differences due to ligand rigidity are even more pronounced: Cu3, with flexible ethylene bridge, is almost non-emissive (PLQY 2\%), while the emission of $\mathbf{C u 2}$ is 18 times more intense due to rigid $o$-phenylene bridge.

The decay kinetics for complexes M1 on cooling from 298 to $77 \mathrm{~K}$ show an increase in excited state lifetimes of three orders of magnitude in the solid state, e.g. from $3.3 \mu$ s to $9.4 \mathrm{~ms}$ for $\mathbf{C u 1}$ (Fig. 5), suggesting that PL at room temperature is due to a thermally activated process. Unlike the behavior in solution, the PL profiles of solid samples of Cu1 and Au1 at $77 \mathrm{~K}$ show a marginal blue-shift with unresolved vibronic structure, indicative of a mixed PL from both ${ }^{1} \mathrm{CT}$ and ${ }^{3} \mathrm{LE}$ states. In 

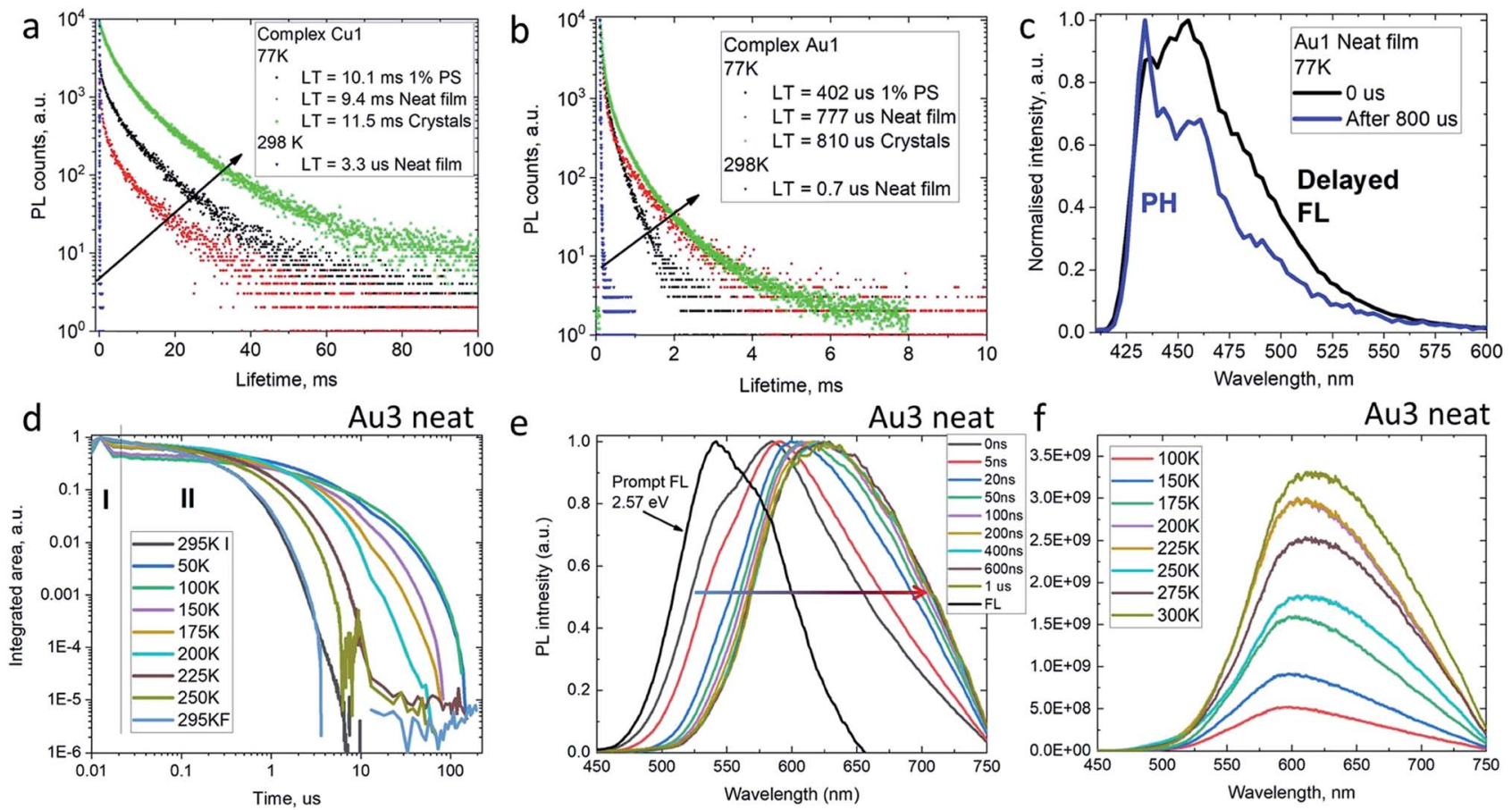

Fig. 5 Emission decay kinetics for complexes Cu1 (a) and Au1 (b) at 298 and $77 \mathrm{~K}$ in the solid state with values for the slow decay; (c) transient emission photoluminescence for Au1 as neat film (excitation at $380 \mathrm{~nm}$ ); (d) temperature-dependent time-resolved PL for Au3 as neat film. (e) Prompt (0-1 ns) and delayed (up to $1 \mu$ s delay) emission spectra at 295 K; (f) varied-temperature PL of Au3 in a neat film in microsecond regime (II).

agreement with this, the data are best fitted by a biexponential model. Time-resolved emission spectroscopy and applying a delay of $800 \mu \mathrm{s}$ confirmed the presence of a ${ }^{3} \mathrm{LE}$ emission with characteristic vibronic structure from the sulfone ligand (see for example Fig. 5c).

To get insight into the activation parameters for flexible amide complexes, we have measured the temperaturedependent transient PL for the bright complex Au3 in neat films. All PL transients show non-exponential kinetics over two distinct time regimes - nanosecond (I) and microsecond (II) as shown on Fig. 5d. The nanosecond regime (I) exhibits no significant $T$ dependence, with a lifetime of $c a$. 3 ns limited by instrument response. Spectral deconvolution allowed extraction of the emission profile for the prompt fluorescence, which is blue-shifted compared to the delayed emission at later times (Fig. 5e). The estimated energy of the prompt fluorescence is in excess of $2.57 \mathrm{eV}$. The microsecond regime (II) shows unstructured and thermally activated luminescence with an activation energy of $94 \mathrm{meV}$ (Fig. S12 $\dagger$ ). The excited state lifetime increases significantly on cooling, from $\tau_{\mathrm{II}}=800 \mathrm{~ns}$ at $300 \mathrm{~K}$ to $52 \mu \mathrm{s}$ below $100 \mathrm{~K}$. We measured photoluminescence intensity as a function of temperature to determine the nature of the thermally activated emission process for complex Au3 and discriminate $v s$. rigidity effects which could also lead to longer excited state lifetime at low temperature. The photoluminescence intensity increases upon warming from 100 to $300 \mathrm{~K}$ (Fig. 5f) thus indicating that it's primarily the radiative rate that is thermally activated and increases with temperature. We observe a red-shift of the delayed emission upon warming for Au3 (Fig. 5f), which is similar to the behavior of the rigid carbazolate systems. ${ }^{15,29}$ The delayed regime dominates the total emission at room temperature, and even on cooling to below $100 \mathrm{~K}$ the phosphorescence spectrum could not be resolved. This prevents identification of the ${ }^{3} \mathrm{LE}$ energy level even after applying long delay up to $200 \mu \mathrm{s}$. Similar behavior has been noted before for other carbene metal amides. ${ }^{15,29,31}$

\section{Mechanochromic properties}

CMA complexes bearing rigid carbazolate ligands are known for their triboluminescence and mechanochromic photoluminescence. ${ }^{2,15}$ This behavior may be expected to be even more pronounced in complexes with flexible amide ligands. Indeed, Au1 shows a mechanochromic response due to its ability to crystallize in two different modifications (vide supra): monoclinic crystals show a bright featureless sky-blue emission at $475 \mathrm{~nm}$, whereas the orthorhombic form emits warm-white light with a maximum at $540 \mathrm{~nm}$ accompanied by a minor peak at $475 \mathrm{~nm}$ (30\% PLQY) (Fig. 6). Both modifications differ slightly in the folding angle of the amide ligand; the behavior of Au1 is therefore likely the result of the different ground state geometries associated with a different angles $\alpha / \beta$, as shown in Fig. 6 . The orthorhombic crystals are very fragile and emit sky-blue light if broken, which explains the origin of the high-energy peak in the warm-white emission profile. Grinding the orthorhombic crystals leads to a hypsochromic shift of $0.32 \mathrm{eV}$ and the disappearance of the broad low energy emission, while the new sky-blue emission almost overlaps with the PL of the monoclinic form. The 

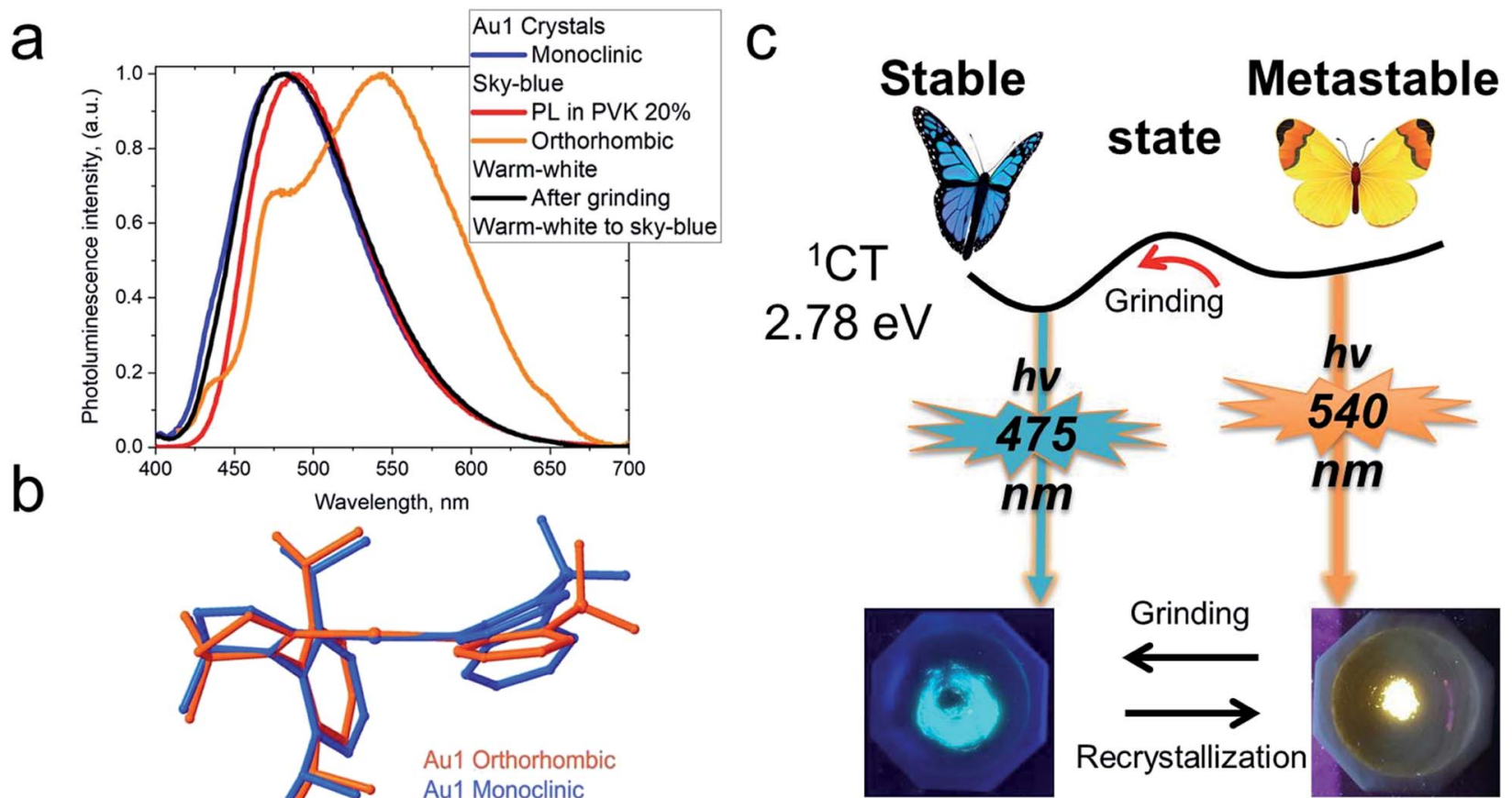

Fig. 6 (a) Solid-state PL of crystals of Au1 in the monoclinic and orthorhombic phases; (b) superposition of the geometries of the Au1 phases determined by single crystal X-ray diffraction; (c) schematic diagram for the interconversion between stable sky-blue (monoclinic) and warmwhite (orthorhombic) emissive forms.

additional emission at $475 \mathrm{~nm}$ for the orthorhombic crystals is therefore due to the mechanoresponsive behavior of this structure. The mechanoresponse of Au1 is irreversible, that is the warm-white emission can only be obtained after recrystallization, and the effect is therefore most probably due to crystal packing. The switch between the stable blue CT and metastable warm white emission can however be exploited for the fabrication of white emissive OLEDs (vide infra).

\section{Electroluminescent (EL) properties}

Vapor-deposited OLEDs incorporating Au3 as emitter were fabricated with the architecture shown in Fig. 7. OLEDs with $20 \mathrm{wt} \%$ dopant in 1,3-bis(9-carbazolyl)benzene (mCP) show EL peaks at $\lambda_{\mathrm{em}}=590 \mathrm{~nm}$ (Fig. 7), while the EL spectra closely match the microsecond-regime PL spectra. Fig. 7 shows the current density-voltage and luminance-voltage characteristics of evaporated devices. External quantum efficiencies (EQEs) (for Au3 of $9.8 \%$ at $100 \mathrm{~cd} \mathrm{~m}^{-2}$ and $9.1 \%$ at $1000 \mathrm{~cd} \mathrm{~m}^{-2}$ ) were achieved, with low roll-off characteristics. The low turn-on voltage of only $2.6 \mathrm{~V}$ indicates a good charge balance in OLED device (Table 3).

Complex Au1 proved insufficiently stable for thermal vapor deposition but suitable for the fabrication of solution-processed OLEDs, with the device architecture ITO/PEDOT:PSS (40 nm)/ TFB $(10 \mathrm{~nm}) / \mathrm{PVK}$ or CBP with $20 \%$ wt Au1 $(40 \mathrm{~nm}) / \mathrm{TPBi}(70$ $\mathrm{nm}) / \mathrm{LiF}(0.8 \mathrm{~nm}) / \mathrm{Al}(100 \mathrm{~nm})$. The OLED glowed initially skyblue, but in the PVK host the emission quickly $(<1 \mathrm{~s})$ broadened and changed to warm-white EL. This transition is likely connected with existence of the two conformational isomers isolated in the crystals of Au1, vide supra (Fig. 6). The initial sky-
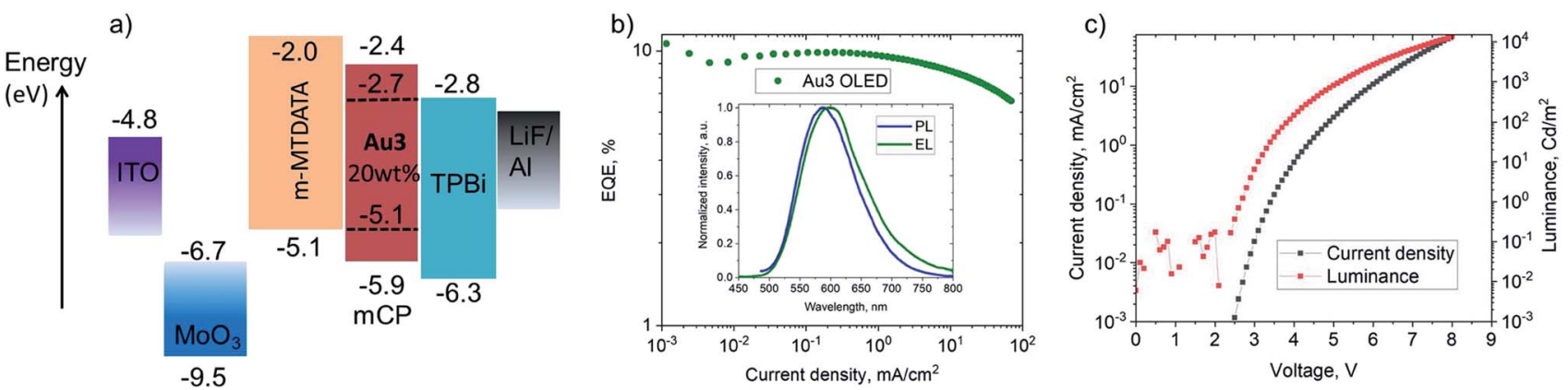

Fig. 7 (a) Vapour-deposited OLED device architecture based on Au3; (b) external quantum efficiencies vs. current density of champion OLEDs with inset showing the electroluminescence (EL) and PL spectra; (c) current density/luminance vs. voltage curve of champion OLEDs. 
Table 3 Performance data of solution and evaporated OLEDs

\begin{tabular}{lllllr}
\hline Dopant [wt\%]/method & $V_{\mathrm{ON}}{ }^{b}[\mathrm{~V}]$ & $\begin{array}{l}\eta_{\mathrm{EQE}, \mathrm{EL}} \\
{[\%](\mathrm{max} .)}\end{array}$ & $\eta_{\mathrm{EQE}, \mathrm{EL}}[\%]\left(100 \mathrm{~cd} \mathrm{~m}^{-2}\right)$ & $\eta_{\mathrm{EQE}, \mathrm{EL}}[\%]\left(1000 \mathrm{~cd} \mathrm{~m}^{-2}\right)$ & $\mathrm{CIE}^{a}(x, y)$ \\
\hline Au1, $[20 \%]$ solution, PVK & 5.4 & 5.8 & 5.5 & 3.6 & $(0.15,0.24)$ \\
Au1, [20] solution, CBP & 5.3 & 4.6 & 4.2 & 2.3 & $(0.18,0.31)$ \\
Au3, [20\%] evaporated, mCP & 2.6 & 11.0 & 9.8 & 9.1 & $(0.53,0.46)$
\end{tabular}

${ }^{a}$ Commission Internationale de l'Éclairage (CIE) color co-ordinates. ${ }^{b} V_{\mathrm{ON}}$ determined at a luminance of $1 \mathrm{~cd} \mathrm{~m}^{-2}$.
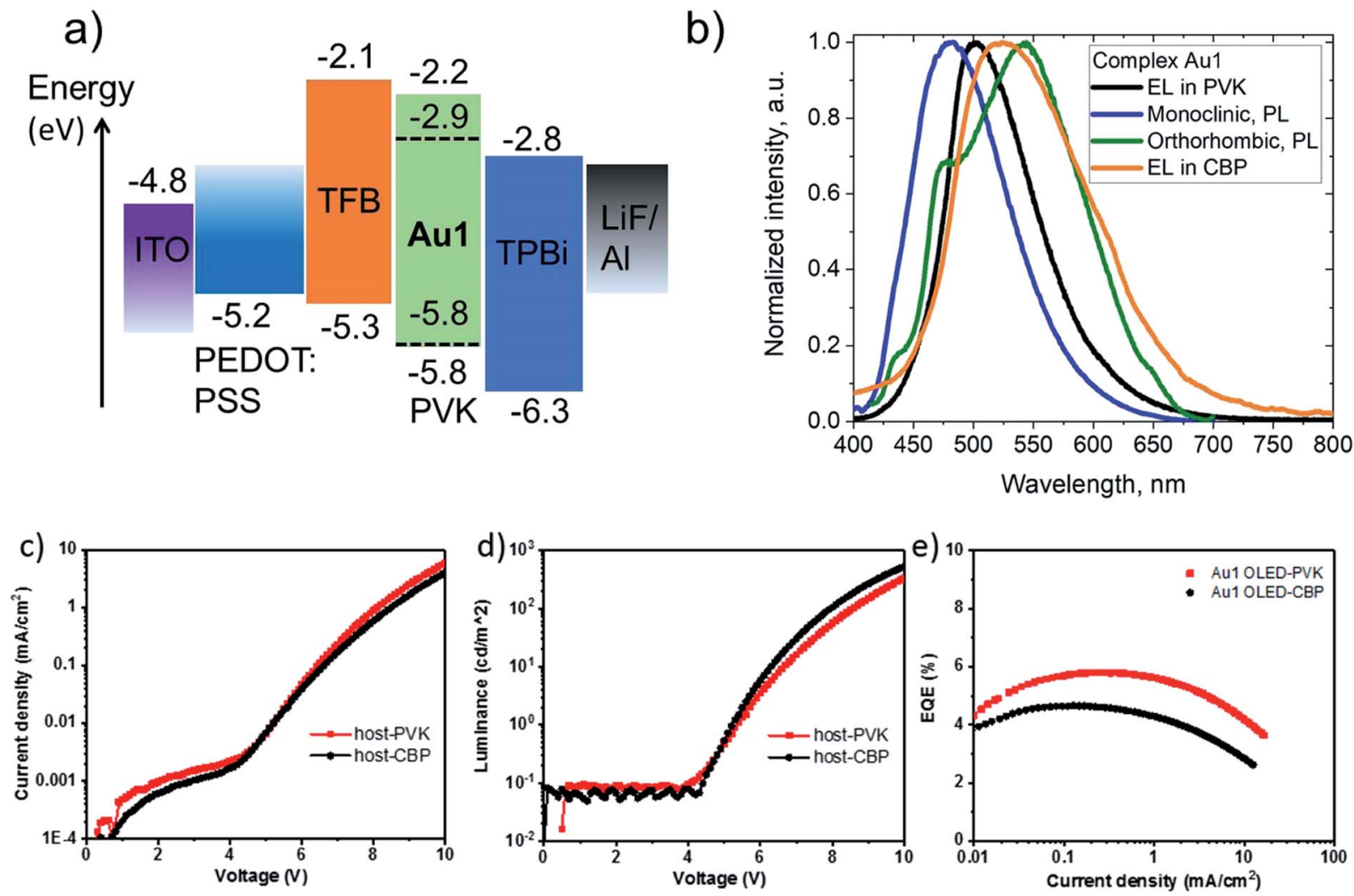

Fig. 8 (a) Solution-processed Au1-based OLED architectures based on 20 wt\% doped PVK as the emissive layer (EML); (b) photoluminescence $(\mathrm{PL})$ and electroluminescence (EL) spectra of different conformers and matrices; (c) current-voltage characteristics and (d) luminance-voltage characteristics for Au1-OLED; (e) external quantum efficiencies vs. current density.

blue EL is tentatively attributed to an emission from the monoclinic form, while the final warm-white EL largely agrees with the averaged PL profiles of the monoclinic and orthorhombic forms (Fig. 8). This explanation was further supported by a second set of Au1 OLEDs in CBP as host, where the EL profile largely coincides with the warm-white PL of the orthorhombic Au1 form. The devices produced peak EQEs of 5.8\% and $4.6 \%$ for Au1 in PVK and CBP hosts, respectively. This is almost the maximum that can be achieved considering the $30 \%$ PLQY value for the warm-white orthorhombic form and 39\% PLQY value in $20 \%$ PVK (Fig. 8 ).

\section{Conclusion}

Carbene metal amide (CMA) complexes of copper and gold of the type (L)M-N $\left(\mathrm{C}_{6} \mathrm{H}_{4}\right)_{2} \mathrm{Z}$, where $\mathrm{Z}=\mathrm{O}, \mathrm{S}, \mathrm{NMe}, \mathrm{CMe}_{2}, \mathrm{SO}_{2}, \mathrm{C}_{2} \mathrm{H}_{4}$ or $o-\mathrm{C}_{6} \mathrm{H}_{4}$ provide a range of photoemissive complexes in which the HOMO-LUMO gap is determined by the electronic characteristics of $\mathrm{Z}$, to give photoluminescence ranging from blue to deep red. The amide-N atoms are part of non-planar, flexible 6and 7-membered heterocycles ("butterfly" conformation). These conformational changes influence the emission behavior. Similar to previously reported CMA compounds with rigid carbazole ligands, ${ }^{\mathbf{1 3 - 1 5 , 2 9 - 3 2}}$ the complexes described here emit predominantly via a thermally activated emission process with sub-microsecond to microsecond excited state lifetimes at room temperature, with radiative rates exceeding $10^{6} \mathrm{~s}^{-1}$. Nitrosubstituents on the amide ligands, on the other hand, quench $\mathrm{L}(\mathrm{M}) \mathrm{LCT}$ processes and luminesce. On cooling to $77 \mathrm{~K}$ the emissions are blue-shifted and excited state lifetimes increase by three orders of magnitude. $\mathbf{M 1}(\mathrm{M}=\mathrm{Cu}$ and $\mathrm{Au})$ complexes emit via both delayed fluorescence and phosphorescence at 77 
K whereas Au3 shows predominantly delayed fluorescence. The magnitude of $k_{\mathrm{nr}}$ increases across the gold and copper series in line with the emission wavelengths, which is consistent with the energy gap law. Proof-of-concept OLEDs were fabricated by thermal vapor deposition, with EQEs of up to $9.8 \%$ at $100 \mathrm{~cd}$ $\mathrm{m}^{-2}$ for a yellow emitter based on the Au3 complex with the 7ring amide ligand. The gold complex Au1 can adopt two conformations which show either blue or warm-white PL; this behavior was exploited in a solution-processed OLED based on Au1 to provide the first example of a CMA-based white-emitting OLED. Conformational flexibility can therefore be employed as a useful design feature to tailor the emission energies and increase the range of readily accessible CMA materials for lightemitting applications.

\section{Conflicts of interest}

The authors declare no competing financial interest.

\section{Acknowledgements}

This work was supported by the European Research Council, the Royal Society and the Academy of Finland. M. B. is an ERC Advanced Investigator Award holder (grant no. 338944-GOCAT). D. C. acknowledges support from the Royal Society (grant no. UF130278 and RG140472). A. S. R. acknowledges support from the Royal Society (grant no. URF $\backslash R \mathbf{R} \backslash 180288$ and RGF $\backslash E A \backslash 181008)$. This work was supported by the EPSRC Cambridge NanoDTC, EP/L015978/1. The computations were made possible by use of the Finnish Grid and Cloud Infrastructure resources (urn:nbn:fi:research-infras-2016072533). J. F. acknowledges his parents for financial support on his PhD. M. L. acknowledges the Academy of Finland Flagship Programme, Photonics Research and Innovation (PREIN), decision 320166.

\section{References}

1 A. S. Romanov, D. Di, L. Yang, J. Fernandez-Cestau, C. R. Becker, C. E. James, B. Zhu, M. Linnolahti, D. Credgington and M. Bochmann, Chem. Commun., 2016, 52, 6379-6382; Chem. Commun., 2018, 54, 3672.

2 A. S. Romanov, C. R. Becker, C. E. James, D. Di, D. Credgington, M. Linnolahti and M. Bochmann, Chem.Eur. J., 2017, 23(19), 4625-4637.

3 M. Gernert, U. Meller, M. Haehnel, J. Pflaum and A. Steffen, Chem.-Eur. J., 2017, 23, 2206-2216.

4 S. Shi, L. R. Collins, M. F. Mahon, P. Djurovich, M. E. Thompson and M. K. Whittlesey, Dalton Trans., 2017, 46, 745-752.

5 V. Lavallo, Y. Canac, C. Prasang, B. Donnadieu and G. Bertrand, Angew. Chem., Int. Ed., 2005, 44, 5705-5709.

6 V. Lavallo, Y. Canac, A. DeHope, B. Donnadieu and G. Bertrand, Angew. Chem., Int. Ed., 2005, 44, 7236-7239.

7 G. D. Frey, R. D. Dewhurst, S. Kousar, B. Donnadieu and G. Bertrand, J. Organomet. Chem., 2008, 693, 1674-1682.

8 M. Soleilhavoup and G. Bertrand, Acc. Chem. Res., 2015, 48, 256-266.
9 M. Melaimi, R. Jazzar, M. Soleilhavoup and G. Bertrand, Angew. Chem., Int. Ed., 2017, 56, 10046-10068.

10 O. Back, M. Henry-Ellinger, C. D. Martin, D. Martin and G. Bertrand, Angew. Chem., Int. Ed., 2013, 52, 2939-2943.

11 A. S. Romanov and M. Bochmann, J. Organomet. Chem., 2017, 847, 114-120.

12 A. S. Romanov and M. Bochmann, Organometallics, 2015, 34, 2439-2454.

13 D. Di, A. S. Romanov, L. Yang, J. M. Richter, J. P. H. Rivett, S. Jones, T. H. Thomas, M. A. Jalebi, R. H. Friend, M. Linnolahti, M. Bochmann and D. Credgington, Science, 2017, 356, 159-163.

14 P. J. Conaghan, S. M. Menke, A. S. Romanov, A. J. Pearson, E. W. Evans, M. Bochmann, N. C. Greenham and D. Credgington, Adv. Mater., 2018, 30, 1802285.

15 A. S. Romanov, S. T. E. Jones, L. Yang, P. J. Conaghan, D. Di, M. Linnolahti, D. Credgington and M. Bochmann, Adv. Opt. Mater., 2018, 6, 1801347.

16 J. Föller and C. M. Marian, J. Phys. Chem. Lett., 2017, 8, 56435647.

17 E. J. Taffet, Y. Olivier, F. Lam, D. Beljonne and G. D. Scholes, J. Phys. Chem. Lett., 2018, 9, 1620-1626.

18 S. Thompson, J. Eng and T. J. Penfold, J. Chem. Phys., 2018, 149, 014304.

19 C. R. Hall, A. S. Romanov, M. Bochmann and S. R. Meech, J. Phys. Chem. Lett., 2018, 9, 5873-5876.

20 Highly Efficient OLEDs - Materials Based on Thermally Activated Delayed Fluorescence, ed. H. Yersin, Wiley-VCH, Weinheim, 2019, ISBN: 978-3-527-33900-6.

$21 \mathrm{H}$. Yersin, R. Czerwieniec, M. Z. Shafikov and A. F. Suleymanova, ChemPhysChem, 2017, 18, 3508-3535.

22 M. J. Leitl, D. M. Zink, A. Schinabeck, T. Baumann, D. Volz and H. Yersin, Top. Curr. Chem., 2016, 374, 25.

23 C. Bizzarri, E. Spuling, D. M. Knoll, D. Volz and S. Bräse, Coord. Chem. Rev., 2018, 373, 49-82.

24 H. Yersin, A. F. Rausch, R. Czerwieniec, T. Hofbeck and T. Fischer, Coord. Chem. Rev., 2011, 255, 2622-2652.

25 Iridium(III) in Optoelectronic and Photonics Applications, ed. E. Zysman-Colman, Wiley, New York, 2017, ISBN: 9781119007135.

26 T.-Y. Li, J. Wu, Z.-G. Wu, Y.-X. Zheng, J.-L. Zuo and Y. Pan, Coord. Chem. Rev., 2018, 374, 55-92.

27 C. Bizzarri, F. Hundemer, J. Busch and S. Bräse, Polyhedron, 2018, 140, 51-66.

28 M.-C. Tang, A. K.-W. Chan, M.-Y. Chan and V. W.-W. Yam, Top. Curr. Chem., 2016, 374, 46.

29 A. S. Romanov, L. Yang, S. E. T. Jones, D. Di, O. J. Morley, B. H. Drummond, A. P. Reponen, M. Linnolahti, D. Credgington and M. Bochmann, Chem. Mater., 2019, 31, 3613-3623.

30 R. Hamze, J. L. Peltier, D. Sylvinson, M. Jung, J. Cardenas, R. Haiges, M. Soleilhavoup, R. Jazzar, P. I. Djurovich, G. Bertrand and M. E. Thompson, Science, 2019, 363, 601606.

31 S. Shi, M. C. Jung, C. Coburn, A. Tadle, M. R. D. Sylvinson, P. I. Djurovich, S. R. Forrest and M. E. Thompson, J. Am. Chem. Soc., 2019, 141, 3576-3588. 
32 R. Hamze, S. Shi, S. C. Kapper, D. S. M. Ravinson, L. Estergreen, M.-C. Jung, A. C. Tadle, R. Haiges, P. I. Djurovich, J. L. Peltier, R. Jazzar, G. Bertrand, S. E. Bradforth and M. E. Thompson, J. Am. Chem. Soc., 2019, 141, 8616-8626.

33 For a preliminary report on color-tuning based on 6-ring amide CMAs see: M. Bochmann, A. S. Romanov, D. J. N. Credgington, D. Di and L. Yang, PCT Internat. Pat. Applic, WO2017/046572 A1, University of East Anglia and Cambridge Enterprises Ltd, https://register.epo.org/ application? number $=\mathrm{EP} 16766064 \& \mathrm{tab}=$ main, 9. 9. 2016.

34 K. Mielech-Łukasiewicz, H. Puzanowska-Tarasiewicz and A. Panuszko, Anal. Lett., 2008, 41, 789-805.

$35 \mathrm{H}$. Zollinger, Color Chemistry, Wiley-VCH, Zurich, 3rd edn, 2001, p. 550.
36 F. Furche and D. Rappoport, in Computational Photochemistry, ed. M. Olivuccim, Elsevier: Amsterdam, 2005, pp. 93-128.

37 H. S. Yu, X. He, S. L. Li and D. G. Truhlar, Chem. Sci., 2016, 7, 5032-5051.

38 F. Weigend, M. Häser, H. Patzelt and R. Ahlrichs, Chem. Phys. Lett., 1998, 294, 143-152.

39 F. Weigend and R. Ahlrichs, Phys. Chem. Chem. Phys., 2005, 7, 3297-3305.

40 D. Andrae, U. Haeussermann, M. Dolg, H. Stoll and H. Preuss, Theor. Chim. Acta, 1990, 77, 123-141.

41 V. M. Vlasov and I. A. Os'kina, Russ. J. Org. Chem., 2002, 38(12), 1705-1718; Zh. Org. Khim., 2002, 38(12), 1767-1780.

42 J. V. Caspar and T. J. Meyer, J. Phys. Chem., 1983, 87(6), 952957. 